\title{
A case with atrophic autoimmune thyroiditis-related hypothyroidism causing multisystem involvement in early childhood
}

\author{
Erdal Kurnaz ${ }^{1}$, Şenay Savaş-Erdeve ${ }^{1}$, Melikşah Keskin $^{1}$, Vehbi Doğan² ${ }^{2}$ Semra Çetinkaya \\ Zehra Aycan ${ }^{1}$ \\ ${ }^{1}$ Clinics Of Pediatric Endocrinology and 2 Pediatric Cardiology Clinic, Dr. Sami Ulus Obstetrics and Gynecology and \\ Pediatrics Training and Research Hospital, Ankara, Turkey.E-mail: erdalkurnaz44@gmail.com \\ Received: 20th November 2015, Revised: 14th March 2016, Accepted: 13th April 2016
}

\begin{abstract}
SUMMARY: Kurnaz E, Savaş-Erdeve Ş, Keskin M, Doğan V, Çetinkaya S, Aycan Z. A case with atrophic autoimmune thyroiditis-related hypothyroidism causing multisystem involvement in early childhood. Turk J Pediatr 2016; 58: 446-451.

The most common reason of acquired hypothyroidism is autoimmune (Hashimoto) thyroiditis. Autoimmune thyroiditis can be atrophic or goitrogenic. Atrophic autoimmune thyroiditis (ATT) related acquired hypothyroidism causes interruption of growth, obesity, and bone age retardation in early ages while goitrogenic thyroiditis has a higher incidence rate and mostly presents with diffuse goiter. We discuss the effects of hypothyroidism on various systems through a case found to have pericardial effusion during the echocardiography performed after cardiac murmur was detected and later diagnosed with ATT related hypothyroidism.
\end{abstract}

Key words: atrophic autoimmune thyroiditis, Kocher-Debre-Semelaigne syndrome, rickets, pituitary expansion.

The most common cause of acquired hypothyroidism in regions where there is no iodine deficiency in children is autoimmune (Hashimoto's) thyroiditis. Autoimmune thyroiditis is 2-4 times more common in girls than in boys. While it is rare in the first 3 years of life, the frequency increases after the age of 6 and reaches its peak in the adolescent period. Diffuse goiter is the dominant clinical picture in most autoimmune thyroiditis patients and atrophic thyroiditis is less commonly seen ${ }^{1,2}$.

Cases with atrophic autoimmune thyroiditis (ATT) related severe hypothyroidism under the age of 5 years have been reported in the literature and delays in the diagnosis have been experienced since ATT is rare in this age group ${ }^{2}$. We present a case who was found to have pericardial effusion in the echocardiography (ECHO) performed at the child cardiology outpatients department for a cardiac murmur and was later diagnosed with ATT related severe hypothyroidism is presented in this article. This case showing multisystem involvement with the disorder in early childhood (pericardial effusion, short stature, Kocher-Debre-Semelaigne syndrome, rickets, pituitary expansion) is presented and discussed with the relevant literature.

\section{Case Report}

A girl aged 3 years and 8 months was referred to the pediatric cardiology department for a cardiac murmur found during pediatric outpatients' examination at another center. A pericardial effusion of $10 \mathrm{~mm}$ had been detected in the echocardiography performed at the pediatric cardiology department and the thyroid function tests requested to determine the etiology revealed a thyroid stimulating hormone (TSH) level of $100 \mathrm{mIU} / \mathrm{ml}(0.6-6.2)$, free thyroxine (sT4) of $0.0 \mathrm{ng} / \mathrm{dl}(0.6-1.25)$, and free triiodothyronine (sT3) of $1.13 \mathrm{pg} / \mathrm{ml}$ $(2.5-5)$. She was then referred to the division of pediatric endocrinology.

The personal history revealed that she was born $1500 \mathrm{~g}$ with $\mathrm{c} / \mathrm{s}$ as one of twins at the 36 th gestational week. There had been 
no negative feedback for the blood obtained within the scope of the postnatal 5th day national hypothyroidism screening program. Neuromotor development milestones in infancy were normal. She had held her head straight at the age of 2 months, sat without support at the age of 6 months and talked at the age of 12 months. There was no kinship between the parents. When the family history was questioned, the father was found to use Lthyroxine (L-T4) treatment. The laboratory results while using daily $1 \times 175 \mathrm{mcg}$ L-T4 treatment were TSH: $1.028 \mu \mathrm{IU} / \mathrm{ml}(0.6-5.5)$, sT4: $1.49 \mathrm{ng} / \mathrm{dl}(0.8-1.9)$, sT3: $3.44 \mathrm{pg} / \mathrm{ml}$ (2-6.5), anti-TG antibody: $19.1 \mathrm{IU} / \mathrm{ml}$ (0-60), anti-TPO: $50.2 \mathrm{IU} / \mathrm{ml}$ (0-60). Thyroid USG of the father revealed right lobe: $20 \times 11 \times 6$ $\mathrm{mm}$, left lobe: $23 \times 10 \times 7 \mathrm{~mm}$, isthmus: 1.6 $\mathrm{mm}$, total volume: $1.5 \mathrm{ml}$. Hypothyroidism was found to be present in the grandmother, father's cousin, and son of the father's uncle. A history of hypothyroidism was not present in the mother or her relatives. The mother's laboratory results were TSH: $1.78 \mu \mathrm{IU} / \mathrm{ml}$ (0.6-5.5), sT4: $0.96 \mathrm{ng} / \mathrm{dl}$ (0.8-1.9), sT3: 2.87 $\mathrm{pg} / \mathrm{ml}$ (2-6.5), anti-TG antibody: <15 IU/ml (0-60), anti-TPO: $33 \mathrm{IU} / \mathrm{ml}(0-60)$.

The vital signs were stable at presentation but the patient had an apathetic appearance. Height was $84.5 \mathrm{~cm}$ (-3.66 sds), body weight $11.3 \mathrm{~kg}(-2.21 \mathrm{sds})$, and bone age 2 years 6 months. The height of the mother and father were $142.7 \mathrm{~cm}$ and $157.5 \mathrm{~cm}$ respectively and the target height was calculated as $143.6 \mathrm{~cm}$ (-2.81 sds). Physical examination revealed dry, pale and myxoedematous skin, $2 / 6$ systolic murmur, and a mitral opening sound on all cardiac foci. There was wrist expansion and muscle hypertrophy that was especially significant in the extremities (Fig. 1). The wrist graph showed irregularity and cupping of the radius and ulna metaphysis (Fig. 2).

The whole blood count at the time of diagnosis revealed $\mathrm{Hb}: 8.01 \mathrm{~g} / \mathrm{dl}$ (10.9-13.7), Hct: $24 \%$ (32-40), WBC: $3700 / \mathrm{mm}^{3}$ (6300-12600), Platelet: $209.000 / \mathrm{mm}^{3}$ (130000-363000), and MCV: $89 \mathrm{fL}$ (70.6-95.6). The iron level was $56 \mu \mathrm{g} / \mathrm{dl}$ (36-184), the serum iron binding capacity $294 \mu \mathrm{g} / \mathrm{dl}$ (260-590), and ferritin $103.9 \mathrm{ng} / \mathrm{ml}$ (6-24). Biochemical parameters were Glucose: $66 \mathrm{mg} / \mathrm{dl}, \mathrm{BUN}$ : $12 \mathrm{mg} / \mathrm{dl}(0-$ 23), Creatinine: $0.57 \mathrm{mg} / \mathrm{dl}(0.3-1.2)$, Calcium:
$8.4 \mathrm{mg} / \mathrm{dl}$ (8.8-10.8), Total protein: $6.9 \mathrm{~g} / \mathrm{dl}$ (6-8), Albumin: $4.3 \mathrm{~g} / \mathrm{dl}$ (3.1-4.8), Phosphorus: $3 \mathrm{mg} / \mathrm{dl}$ (4.5-5.5), Sodium: $139 \mathrm{mEq} / \mathrm{L}$ (135143), Potassium: $4.2 \mathrm{mEq} / \mathrm{L}$ (3.1-5.5), Alkaline

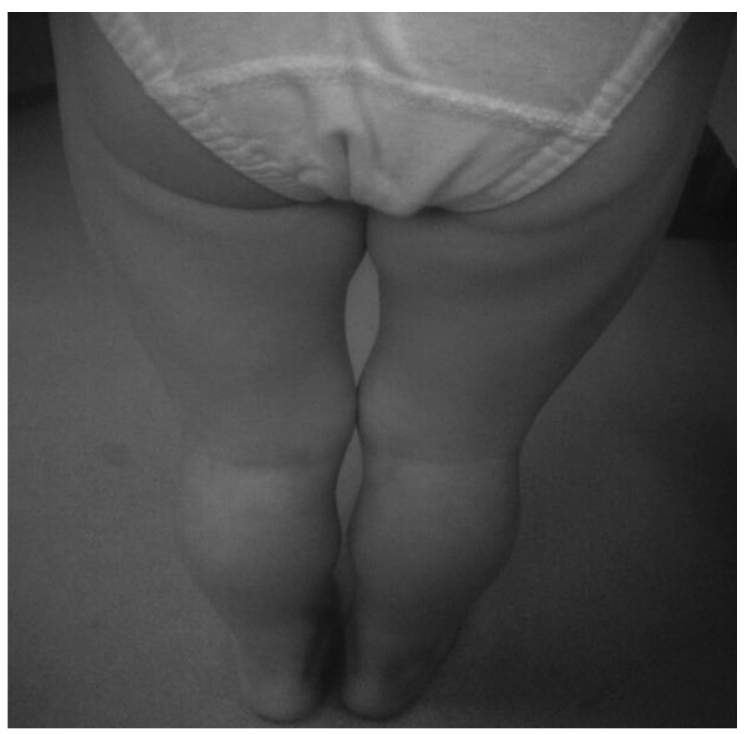

Fig. 1. Image of muscle hypertrophy

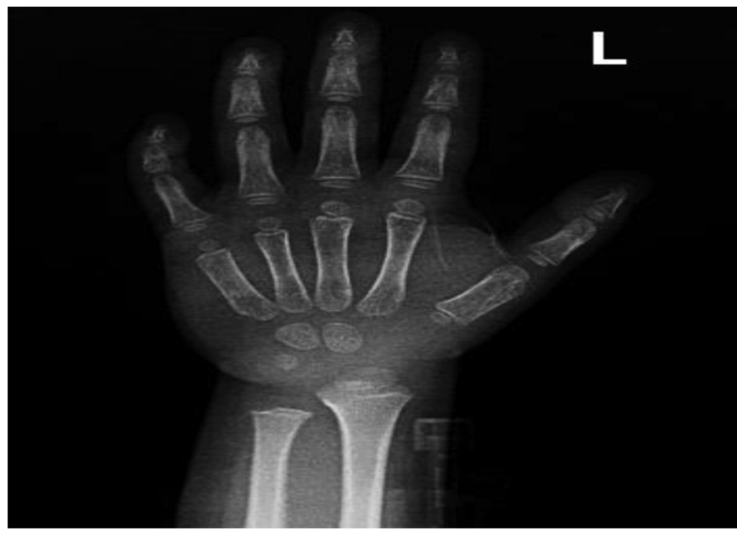

Fig. 2. Irregularity and cupping of the radius and ulna metaphysic before treatment

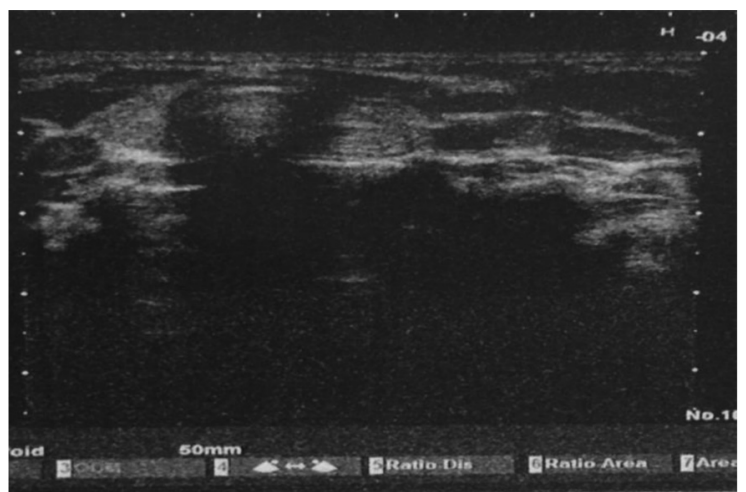

Fig. 3. USG image of atrophic thyroid tissue due to thyroiditıs in the thyroid fossa. 
phosphatase: $55 \mathrm{U} / \mathrm{L}(<500)$, AST: $36 \mathrm{U} / \mathrm{L}$ (<48), ALT: $17 \mathrm{U} / \mathrm{L}$ (0-39), Cholesterol: 518 $\mathrm{mg} / \mathrm{dl}$ (83-211), LDL cholesterol: $444.4 \mathrm{mg} / \mathrm{dl}$ (38-140), HDL Cholesterol: $44.4 \mathrm{mg} / \mathrm{dl}$ (35), Triglyceride: $146 \mathrm{mg} / \mathrm{dl}$ (35-110), Creatine

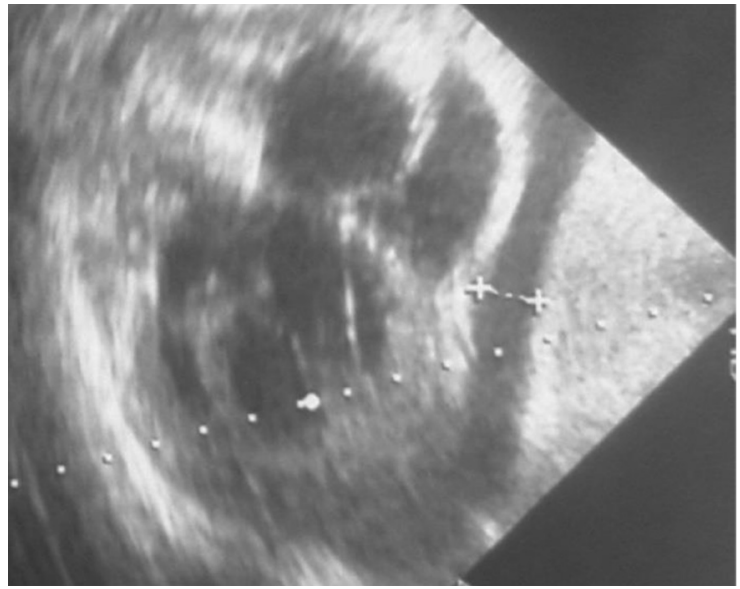

Fig. 4. Pericardial effusion on echocardiography

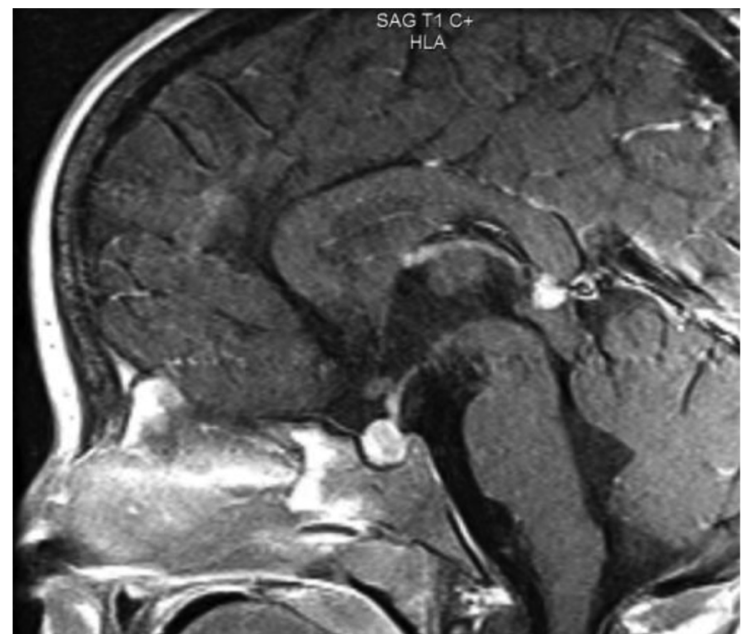

Fig. 5. Microadenoma at the sagittal T1 image

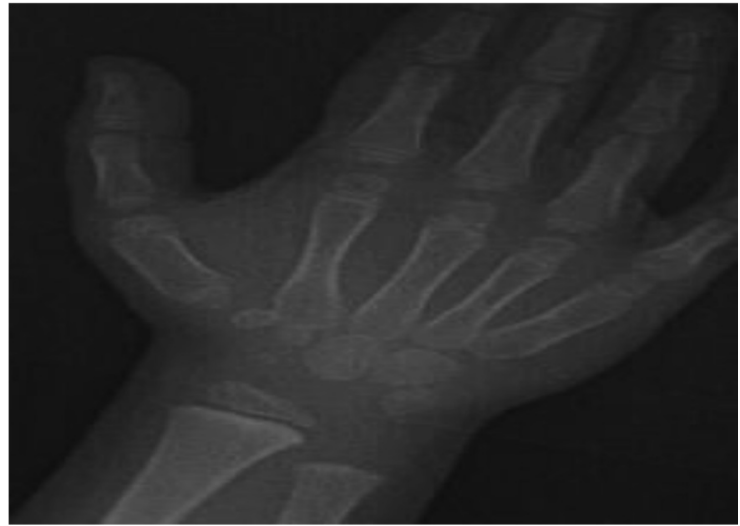

Fig. 6. Hand graph returned to normal after L-Thyroxine replacement was started kinase: 446 IU/L (34-204), LDH: $381 \mathrm{IU} / \mathrm{L}$ (142-297), Parathormone (PTH): $26.7 \mathrm{pg} / \mathrm{ml}$ (11-67), and 25-OH D vitamin: $15.7 \mu \mathrm{g} / \mathrm{L}$ (1080). Thyroid function tests revealed TSH: 150 $\mu \mathrm{IU} / \mathrm{ml}$ (0.6-6.3), sT4: $0.31 \mathrm{ng} / \mathrm{dl}$ (0.9-2.1), sT3: $0.43 \mathrm{pg} / \mathrm{ml}$ (2-6.5), Anti-TPO: $148.4 \mathrm{IU} /$ $\mathrm{ml}$ (0-60), anti-TG antibody: $500 \mathrm{IU} / \mathrm{ml}(0-$ 60 ), iodine in urine: $102.1 \mu \mathrm{g} / \mathrm{L}(100-700)$, Thyroglobulin: $3.63 \mathrm{ng} / \mathrm{ml}(0-60)$, and TSH receptor blocking antibody: $8.77 \mathrm{U} / \mathrm{L}$ (0-14). Thyroid ultrasonography results were right lobe $14 \times 6 \times 10 \mathrm{~mm}(0.43 \mathrm{ml})$, left lobe 15 x $6 \times 10 \mathrm{~mm}(0.46 \mathrm{ml})$, isthmus $2.3 \mathrm{~mm}$ in thickness, parenchyma heterogeneous with millimetric pseudonodule formations in some places and contour lobulations in both lobes. Thyroid volume was $0.89 \mathrm{ml}(0.9-4.9 \mathrm{ml})$ and was small for the age of our patient (Fig. 3).

Pericardial effusion thickness was $6.8 \mathrm{~mm}$ in the posterior wall, $8.6 \mathrm{~mm}$ in the anterior wall and $11 \mathrm{~mm}$ in the apical region of the left ventricle on ECHO (Fig. 4).

Pituitary MRI was requested for the patient who had severe growth retardation together with acquired autoimmune thyroiditis-related hypothyroidism and revealed a pituitary gland height of $7 \mathrm{~mm}$ at the central part and contour lobulation towards the superior. It was reported that a lesion resembling a microadenoma $5 \times 3 \mathrm{~mm}$ in size was observed and was more especially evident at the sagittal T1 image compared to the normal pituitary gland in the post-contrast series in this section (Fig. 5).

The patient was started on L-T4 treatment at a dose of $6.5 \mu \mathrm{g} /$ day with the diagnosis of AAT. The dose was gradually increased up to $50 \mu \mathrm{g} /$ day. The TFT value at the 4 th week of this treatment was found to be euthyroid. The pericardial effusion decreased to a minimum level on the 3rd week of treatment and disappeared completely after 6 weeks. The follow-up blood lipid and creatinine levels regressed to normal after the 4th month of treatment. The height increased $8 \mathrm{~cm}$ in 10 months with L-T4 treatment.

Tubular phosphate reabsorption (TPR) was calculated as $83.5 \%$ in the patient whose serum 25-OH D vitamin and phosphorus levels were low. The blood phosphorus level, TPR and hand graph returned to normal after L-T4 replacement was started (Fig. 6). 
Follow-up pituitary MRI after 6 months of treatment was completed, showed a pituitary gland height of $4.1 \mathrm{~mm}$ and there was nodular lesion about $1.7 \mathrm{~mm}$ in size showing less contrast enhancement than the other areas in the left part of the pituitary gland (Fig. 7). Pituitary MRI was normal at the 18th month of treatment (Fig. 8).

\section{Discussion}

Autoimmune thyroiditis is the most common cause of acquired hypothyroidism with or without goiter. Acquired autoimmune hypothyroidism is common in late childhood and adolescence but very rare in the first few years of life $^{3}$. A review of the cases with AAT reported in the literature revealed that 3 cases

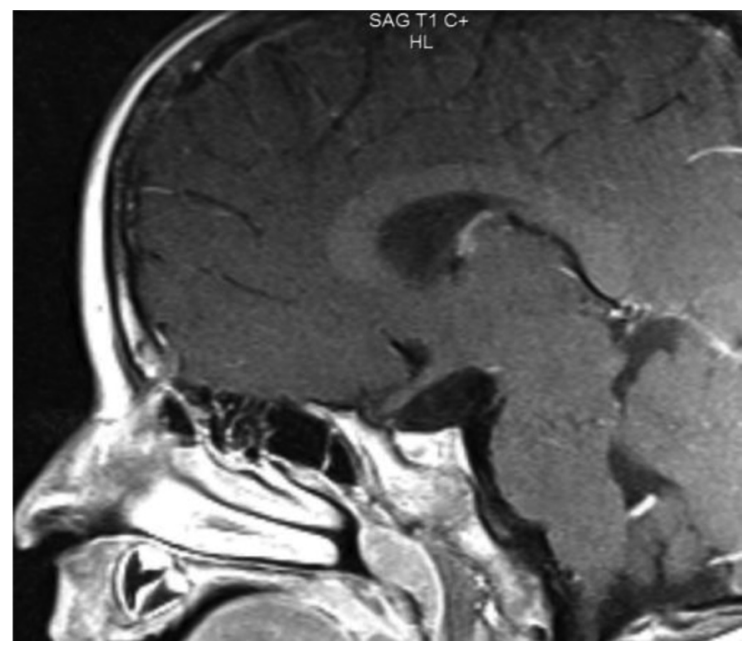

Fig. 7. Less contrast enhancement than the other areas in the left part of the pituitary gland

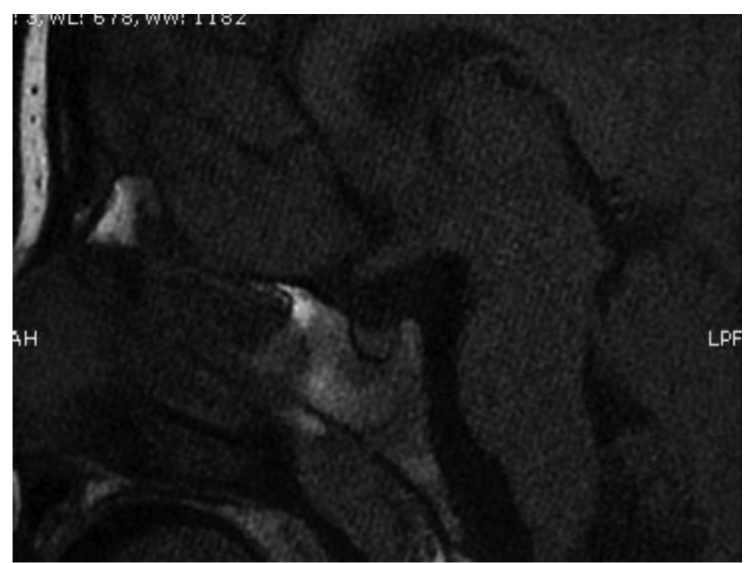

Fig. 8. Normal pituitary MR image at 18th month of treatment
(4 mo, $7 \mathrm{mo}, 7 \mathrm{mo}$ ) had developed AAT as a component of the polyglandular autoimmune endocrine insufficiency syndrome ${ }^{4-6}$. Atrophic autoimmune thyroiditis was diagnosed in a severe combined immunodeficiency case when 3 months old ${ }^{7}$. 7 very young children diagnosed with isolated AAT were found in the literature. A 2-year-old case was reported by Joergensen et al. ${ }^{8}$. A total of 4 cases diagnosed with AAT including 2 cases diagnosed at the age of 1.1 years and 2 years and 9 months were reported by Foley et al. ${ }^{9}$. Congenital hypothyroidism screening was found normal and TSH receptor (TSHR) blocking antibodies (Abs) was negative in all 4 cases as in our case and Tranconi GM et al. ${ }^{10}$ reported 2 cases that were diagnosed with AAT in the first 3 years of life TSHR Abs was negative in 4 of these 7 cases reported so far. Although TSHR Abs are known to play a role in the development of AAT-related hypothyroidism, there are studies where no significant relationship was found between AAT and TSHR Abs positivity. TSHR Abs was requested for AAT etiology but was also negative in our case. The etiology and pathogenesis are not entirely clear in AAT cases with negative TSHR Abs, as in our case ${ }^{1,2}$. Atrophic autoimmune thyroiditisrelated hypothyroidism in early childhood can be overlooked as there is no goiter ${ }^{2,11}$. Atrophic autoimmune thyroiditis-related severe hypothyroidism was also overlooked in our case until complications occurred.

Atrophic autoimmune thyroiditis is seen in earlier ages compared to cases with goiter and growth is reported to be affected in this type with severe hypothyroidism occurring more commonly. Our case is interesting because multisystem involvement due to AAT-related severe hypothyroidism was present with the heart, skeletal muscle, bone, pituitary and kidney tubules being affected.

Pericardial and pleural effusion is a rare complication of severe hypothyroidism in children and hypothyroidism-related pericardial and pleural effusion in childhood has mostly been reported in patients with Down syndrome. It is believed that pericardial effusion develops due to increased capillary permeability and disruption of lymphatic drainage and it rarely progresses to pericardial tamponade. The slow accumulation of effusion fluid in the patients 
and the capacity of the pericardium to expand prevents tamponade and the effusion regresses with L-T4 treatment ${ }^{12-15}$. Our patient similarly improved in 6 weeks with L-T4 treatment without any need for an intervention such as effusion surgery or pericardiocentesis.

Long-term hypothyroidism causes pseudohypertrophy of the muscles that is more pronounced in the extremities and is also known as the Kocher-Debre-Semelaigne syndrome. The pathogenesis is not clear but the condition should be kept in mind ${ }^{16-18}$. Our patient also had pseudohypertrophy that was more evident in the extremity muscles (Fig. 1). The pseudohypertrophy in our patient improved with L-T4 treatment as in other cases reported in the literature ${ }^{17,18}$.

Pituitary gland enlargement can be seen with hyperplasia of the thyrotropic cells in congenital and acquired hypothyroidism ${ }^{19}$. Avoiding unnecessary surgical intervention and monitoring the patient with pituitary MRI are recommended for this condition that is reversible with treatment ${ }^{18-20}$. The increased pituitary gland height and the microadenoma in our case regressed with medical treatment, similar to the literature.

The TPR level of the case at the time of diagnosis was calculated as $83.5 \%$. Thyroid hormone increases phosphate reabsorption at the proximal tubular cells ${ }^{21}$. TPR was seen to return to normal after the patient became euthyroid. The $25 \mathrm{OH} \mathrm{D}$ vit level of the patient was at the lower limit. However, there was no elevation of the PTH level. This indicates that the low TPR level was related to hypothyroidism. This case is an informative and interesting case in terms of showing the effect of thyroid hormones on TRP.

In conclusion, atrophic autoimmune thyroiditisrelated hypothyroidism can be overlooked due to lack of goiter and can have serious and irreversible results in various systems. Early diagnosis is important to correct the negative effects of severe hypothyroidism on the heart, skeletal muscle, bone, kidney and pituitary gland.

\section{REFERENCES}

1. LaFranchi SH. Thyroiditis. In: Kliegman RM, Stanton BF, St Geme JW, Schor NF, Behrman RE (eds). Nelson Textbook of Pediatrics (19th ed). Philadelphia: Elsevier Saunders; 2011: 1879-1881.

2. Matsuura N, Konishi J, Yuri K, et al. Comparison of atrophic and goitrous auto-immune thyroiditis in children: clinical, laboratory and TSH-receptor antibody studies. Eur J Pediatr 1990; 149: 529-533.

3. Tronconi GM, Caiulo S, Di Frenna M, et al. Rare cases of autoimmune hypothyroidism in young children. J Pediatr Endocrinol Metab 2013; 26: 963-966.

4. Powell BR, Buist NR, Stenzel P. An X-linked syndrome of diarrhea, polyendocrinopathy, and fatal infection in infancy. J Pediatr 1982; 100: 731-737.

5. Savage MO, Mirakian R, Wozniak ER, et al. Specific autoantibodies to gut epithelium in two infants with severe protracted diarrhoea. J Pediatr Gastroenterol Nutr 1985; 4: 187-195.

6. Ostergaard GZ, Jacobsen BB. Atrophic, autoimmune thyroiditis in infancy. A case report. Horm Res 1989; 31: 190-192.

7. Kaino Y, Otoh Y, Tokuda K, et al. Acquired hypothyroidism in a very young infant with Omenn's syndrome. J Pediatr 2000; 136: 111-113.

8. Joergensen JV, Oerbeck B, Jebsen P, et al. Severe hypothyroidism due to atrophic thyroiditis from second year of life influenced developmental outcome. Acta Paediatr 2005; 94: 1049-1054.

9. Foley TP Jr, Abbassi V, Copeland KC, Draznin MB. Brief report: hypothyroidism caused by chronic autoimmune thyroiditis in very young infants. N Engl J Med 1994; 330: 466-468.

10. Tronconi GM, Caiulo S, Di Frenna M, et al. Rare cases of autoimmune hypothyroidism in young children. $\mathrm{J}$ Pediatr Endocrinol Metab 2013; 26: 963-966.

11. Chandanwale SS, Gore CR, Bamanikar SA, et al. Cytomorphologic spectrum of Hashimoto's thyroiditis and its clinical correlation: a retrospective study of 52 patients. Cytojournal 2014; 29; 11: 9.

12. Levy PY, Corey R, Berger P, et al. Etiologic diagnosis of 204 pericardial effusions. Medicine (Baltimore) 2003; 82: 385-391.

13. Mittnacht J, Schmidt F, Ebinger F, Bettendorf M. Unusual clinical presentation of primary hypothyroidism in a very young infant caused by autoimmune thyroiditis: case report and update of the literature. Eur J Pediatr 2007; 166: 881-883.

14. Sanda S, Newfield RS. A child with pericardial effusion and cardiac tamponade due to previously unrecognized hypothyroidism. J Natl Med Assoc 2007; 99: 14111413.

15. Hayford JT, Schieken RM, Thompson RG. Cardiac function in primary hypothyroidism. Am J Dis Child 1980; 134: 556-559.

16. Dharaskar P, Tullu MS, Lahiri KR, et al. Case report Kocher-Debre-Semelaigne syndrome with pericardial effusion. Indian J Med Sci 2007; 61: 527-530. 
17. Tullu MS, Udgirkar VS, Muranjan MN, et al. KocherDebre- Semelaigne syndrome: hypothyroidism with muscle pseudohypertrophy. Indian J Pediatr 2003; 70: 671-673.

18. Tullu MS, Bavdekar SB. Kocher-Debre-Semelaigne syndrome. In: Gupta S, editor. Recent Advances in pediatrics, Special Volume on Pediatric Endocrinology. Jaypee Brothers: New Delhi; 2004: 159-162.

19. Sarlis NJ, Brucker-Davis F, Doppman JL, Skarulis MC. MRI-demonstrable regression of a pituitary mass in a case of primary hypothyroidism after a week of acute thyroid hormone therapy. J Clin Endocrinol Metab 1997; 82: 808-811.
20. Simssek E, Simșek T, Savaş-Erdeve S, et al. Pituitary hyperplasia mimicking pituitary macroadenoma in two adolescent patients with long-standing primary hypothyroidism: case reports and review of literature. Turk J Pediatr 2009; 51: 624-630.

21. Ishiguro M, Yamamoto H, Masuda M, et al. Thyroid hormones regulate phosphate homoeostasis through transcriptional control of the renal type IIa sodium-dependent phosphate co-transporter (Npt2a) gene. Biochem J 2010; 427: 161-169. 